\title{
Quality of life of children and adults following cardiac surgery for congenital heart disease: A Mexican cohort
}

\author{
Calidad de vida en niños y adultos después de cirugía para cardiopatías congénitas: \\ primera cohorte mexicana
}

\author{
Elizabeth Aguilar-Alaniz ${ }^{*}$, Rodrigo Reyes-Pavón², Jacob Van-der-Ende³, Fernando J. Félix-Orta², \\ Itzel Delgado-Servín-de la Mora², Ángel Aroca-Peinado ${ }^{4}$, Luz Polo-López ${ }^{4}$, y Juan C. Moreno-Salas ${ }^{5}$
}

${ }^{1}$ Department of Cardiothoracic Surgery, Centenario Hospital Miguel Hidalgo, Aguascalientes, Aguascalientes, México; ${ }^{2}$ Department of Medicine, Health Sciences Center, Universidad Autónoma de Aguascalientes, Aguascalientes, México; ${ }^{3}$ Department of International Health and Tropical Medicine, Leidschendam, The Netherlands; ${ }^{4}$ Department of Pediatric Cardiovascular Surgery, Alianza Interhospitalaria de los Hospitales Universitarios La Paz-Ramón y Cajal, Madrid, España; ${ }^{5}$ Department of Pediatric Cardiology, Centenario Hospital Miguel Hidalgo, Aguascalientes, México

\begin{abstract}
Objective: The real burden of (congenital heart defects $[C H D]$ ) and the improvement after surgical correction or palliation is both reflected in the quality of life $(Q O L)$. There are few studies in Latin-America that evaluate QoL in the CHD population. The purpose of this study was to measure the QoL after corrective or palliative surgery for CHD. Materials and methods: An observational, cross-sectional, and comparative study was carried out at the Miguel Hidalgo Centennial Hospital. Patients from 8 to 18 years old who underwent surgery for CHD were included during a period of 8 months. A total of 40 patients were included, together with a group of 80 healthy controls. From all participants, a KIDSCREEN-52 questionnaire was taken. A comparative analysis of the results was performed. Results: Overall, patients with cardiac surgery had better QoL indexes than healthy controls $(p<0.0001)$. The difference was greatest in moods and emotions, autonomy, and parent relations. Conclusions: Self-perception of QoL in post-operative patients for congenital heart disease is similar and in certain dimensions higher than the healthy population, possibly due to socioeconomic differences, parental care, and styles of coping with their disease. Higher complexity studies that include psychosocial variables and parental perception are required, and a better understanding of the QoL determinants will improve the attention provided to the patient and their families.
\end{abstract}

Key words: Quality of life. Outcomes. Neurocognitive deficits. Comorbidity Kidscreen.

\section{Resumen}

Objetivo: Los efectos de las cardiopatías congénitas en los pacientes, así como la mejoría después de la paliación o la corrección quirúrgica, se reflejan en la calidad de vida (CV). Hay pocos estudios en Latinoamérica que evalúen la CV en esta población. El objetivo de este artículo es notificar la CV posterior a la operación paliativa o correctiva para defectos cardíacos

Correspondence:

*Elizabeth Aguilar-Alaniz

E-mail: eaguilar12598@gmail.com
Date of reception: $28-02-2020$

Date of acceptance: $19-03-2020$

DOI: 10.24875/ACME.M21000187
Available online: $23-02-2021$

Arch Cardiol Mex (Eng). 2021;91(1):33-40 www.archivoscardiologia.com 2604-7063 / @ 2020 Instituto Nacional de Cardiología Ignacio Chávez. Published by Permanyer. This is an open access article under the CC BY-NC-ND license (http://creativecommons.org/licenses/by-nc-nd/4.0/). 
congénitos. Material y métodos: Se llevó a cabo un estudio observacional, transversal y comparativo en el Centenario Hospital Miguel Hidalgo. Durante un período de ocho meses se incluyó a pacientes de 8 a 18 años sometidos a una intervención para cardiopatías congénitas. Se reunió a dos grupos de 40 pacientes y 80 controles sanos, pareados por edad y sexo. A cada participante se le aplicó el cuestionario KIDSCREEN-52 y se realizó un análisis comparativo de los resultados. Resultados: LoS pacientes sometidos a operación cardíaca tuvieron mejores índices de CV que los controles sanos $(p<0.0001)$. La mayor diferencia se obtuvo en los aspectos de estado de ánimo y emociones, autonomía y relación con los padres. Conclusiones: La autopercepción de la CV después de una intervención para cardiopatías congénitas es similar y, en ciertas dimensiones, mejor que la de la población sana, tal vez por diferencias socioeconómicas, atención de los padres y modelos de adaptación a la enfermedad. Se requieren estudios más extensos que incluyan variables psicosociales y percepción parental. Una mayor comprensión de los determinantes de la CV podría mejorar la atención ofrecida al paciente y su familia.

Palabras clave: Calidad de vida. Déficit neurocognitivo. Comorbilidades Kidscreen.

\section{Introduction}

Congenital heart defects (CHDs) account for almost a third of all congenital defects. Their prevalence varies by continent and country and the overall prevalence has risen from 0.6/1000 newborns before 1994 to $9.1 / 1000$ newborns after 1995'. In Latin-America, CHDs are the second highest cause of death in infants younger than 1 year old ${ }^{2}$. In Mexico, the real prevalence is unknown due to lacking epidemiological reports. Regional centers report a prevalence of 7.4/1000 newborns ${ }^{3}$.

Medical and surgical advances have improved the survival rate of patients with $\mathrm{CHD}$. Defects that were previously untreatable nowadays can be corrected surgically ${ }^{4,5}$. A decade ago, evaluation of the health state of children with $\mathrm{CHD}$ only considered their physical capacity and the possible residual anatomical defects. However, the real burden of $\mathrm{CHD}$ is reflected in the quality of life (QoL) of the patients ${ }^{6,7}$. The World Health Organization defines QoL as an individual's perception of their position in life, in the context of the culture and value systems in which they live, and it is affected by the person's physical health, psychological state, personal beliefs, social relationships, and relationship to prominent features in their environment ${ }^{8}$.

Evaluating QoL in patients is an important practice because it allows for better communication between patients, parents, and health service providers, prioritizing health-related problems based on parental and/ or patient preferences; it is also a specific way to monitor changes in response to a specific therapy through time and to perform screening of other physical or psychosocial health issues ${ }^{9}$.

There is an inherent subjectivity in the self-perception of QoL, which has led to designing valid and reproducible methods for its evaluation, consisting of questionnaires that generate scales to measure the different dimensions of the health-related QoL. In 2002, there were 92 different instruments to measure QoL, 45 of them being general, or not designed for a specific disease. Such instruments represent a complementary method of evaluating the response to certain treatments or therapies ${ }^{10}$.

A few attempts have been made to measure QoL in Latin-America population, using different generic questionnaires, in countries such as Cuba and Chile. In some cases, the non-validated translated versions have been used ${ }^{11,12}$. Brazil has the higher methodological quality studies ${ }^{13}$.

The KIDSCREEN-52 questionnaire is a standardized test designed to assess generic health-related QoL in healthy and chronically ill children and adolescents. In the development, generation, and validation of the questionnaire, dimensions and items relevant to respondents in different countries of Europe were identified, becoming the first transnational instrument. It has also been validated in the Spanish language and is linguistically specified for Mexico ${ }^{14,15}$.

Our hospital is a regional referral center for the correction of CHD. Unfortunately, there are no clinical studies in Mexican population to evaluate the impact of the interventions on CHD patients. The objective of this study is to evaluate the QoL in children aged 8-18 years old in Aguascalientes after corrective or palliative surgery for CHD.

\section{Materials and methods}

\section{Study design}

An observational, cross-sectional, and descriptive study was designed with children and adolescents from 8 to 18 years and took place between June 2017 and January 2018 (8 months) at the Miguel Hidalgo Centennial Hospital and five different schools (private and state schools): two elementary schools, two middle schools, and one high school. 


\section{Patients and controls}

Miguel Hidalgo Centennial Hospital receives patients from the state of Aguascalientes and surrounding communities (both urban and rural). There is a social agenda for patients without resources or social security that covers the economic costs of the treatment of congenital heart diseases. Clinical files of patients who underwent corrective or palliative surgery for CHD from 2000 to $2012(n=642)$ were examined. Patients who were deceased at the time of the study $(n=71)$, younger than 8 years old or older than 18 years old $(n=167)$ or who had any recorded degree of cognitive impairment (previously evaluated by the genetics clinic and the psychology department) ( $n=68$ ) were excluded from the study. Of the 336 patients remaining, 289 had incomplete files or were lost to follow up and were excluded as well.

The control group was formed with children and adolescents of four different schools, paired by age to our patients.

\section{Instrument}

The KIDSCREEN-52 self-report questionnaire in the Mexican validated version was used. It measures 10 dimensions of health-related QoL: "physical Well-being" explores the level of physical activity, energy, and fitness; "Psychological well-being" includes positive emotions and satisfaction with life; "moods and emotions" covers how much the patient experiences depressive moods and emotions and stressful feelings; "self-perception" includes self-appearance of the body, security, and satisfaction about him/herself; "autonomy" looks at the opportunity given to the patient to create social and leisure time; "parent relations and home life" explores the quality of interaction between patient and parent; "social support and peers" examines the quality of the interaction between the patient and peers as well as their perceived support; "school environment" explores a patients perception of his/her cognitive capacity, learning and concentration and includes the patients satisfaction with his/her ability and performance at school; "social acceptance" covers the aspect of feeling rejected by peers in school, and finally, "financial resources" measures the perceived quality of the financial resources ${ }^{14,15}$.

The questionnaire's internal consistency values (Cronbach's alpha) range between 0.76 (for social acceptance) and 0.89 (for financial support) on the different dimensions. It is scored as Rasch scales and translated into T-values; means and standard deviations were calculated. Higher means are indicative of higher QoL ${ }^{15}$.

The study complies with the Declaration of Helsinki and it was approved by the Ethics Committee of the hospital. Informed consent was obtained by patients, patients' parents, and controls before the interview. Each child answered the questionnaire by himself. The questionnaire was taken from the patients during a hospital appointment. In nine cases, the patient was unable to visit the hospital due to their actual location and the interview was taken by phone. The interview was performed by the same interviewer and in the same manner each time, caring for the fully understanding of the questions. The questionnaire for the controls was taken at school.

\section{Statistical analysis and proprietary software}

Descriptive data are presented as mean \pm standard deviation. The KIDSCREEN-52 instrument was analyzed according to its manual ${ }^{15}$. Statistical analysis was performed with IBM SPSS Statistics version 23. Means and standard deviations were calculated for each dimension for each group. Group comparisons were performed with the parametric Student's t-test. $p<0.05$ was considered statistically significant. Graphical analysis was done with the software GraphPad Prism version 5 .

\section{Results}

\section{Patients' demographics}

Out of 40 patients interviewed, $60 \%$ were female $(n=24)$ and $40 \%$ were male $(n=16)$ with a mean age of 11.6 years. Twenty-two patients were at the age between 8 and 11 years and 18 patients were at the age between 12 and 18 years. Before the procedures, 28 patients had acyanotic heart defects and 12 patients had cyanotic heart defects, respectively (Table 1), but cyanosis was corrected in all cases after the surgery. The most frequent diagnosis was ventricular septal defect $(30 \%)$ followed by patent ductus arteriosus (17.5\%). All diagnoses are shown in Table 2.

Thirty-nine patients underwent corrective surgery (in 29 patients, a cardiopulmonary bypass was needed, with $99.7 \pm 50.5 \mathrm{~min}$ of cardiopulmonary bypass time and $61.7 \pm 35.6 \mathrm{~min}$ of aortic cross-clamp time). Only one patient underwent a palliative surgery consisting 
Table 1. Demographics of the patients

\begin{tabular}{|l|l|l|}
\hline & $\mathbf{n}$ & $\%$ \\
\hline 8-11 years of age & 22 & 55 \\
\hline $12-18$ years of age & 18 & 45 \\
\hline Comorbidities & 9 & 23 \\
\hline Acyanotic CHD & 28 & 70 \\
\hline Cyanotic CHD & 12 & 30 \\
\hline Corrective procedure & 39 & 98 \\
\hline Palliative procedure & 1 & 2 \\
\hline Underwent surgery with CPB & 29 & 73 \\
\hline No CPB & 11 & 27 \\
\hline Previous procedures & 10 & 25 \\
\hline No previous procedures & 30 & 75 \\
\hline Reinterventions & 7 & 18 \\
\hline No reinterventions & 33 & 82 \\
\hline RACHS-1 & 13 & 32 \\
\hline RACHS-2 & 23 & 58 \\
\hline RACHS-3 & 4 & 10 \\
\hline
\end{tabular}

CHD: congenital heart defect; CPB: cardiopulmonary bypass; RACHS: Risk Adjustment for Congenital Heart Surgery.

Table 2. Anatomical diagnosis of the patient group ( $n=40$ )

\begin{tabular}{|l|l|l|}
\hline Congenital heart defect & $\mathbf{n}$ & $\%$ \\
\hline Ventricular septal defect & 12 & 30 \\
\hline Patent ductus arteriosus & 7 & 17.5 \\
\hline Tetralogy of fallot & 5 & 12.5 \\
\hline Atrial septal defect & 3 & 7.5 \\
\hline Anomalous pulmonary venous connection & 3 & 7.5 \\
\hline Aortic coarctation & 2 & 5 \\
\hline Subpulmonary valve stenosis & 1 & 2.5 \\
\hline Aortic coarctation associated with ventricular & 1 & 2.5 \\
\hline septal defect & & 1 \\
\hline Atrioventricular septal defect & 2.5 \\
\hline Complex cyanotic heart defect & 1 & 2.5 \\
\hline Double outlet right ventricle & 1 & 2.5 \\
\hline Aortopulmonary window & 1 & 2.5 \\
\hline Pulmonary valve stenosis & 1 & 2.5 \\
\hline Double chambered right ventricle & 1 & 2.5 \\
\hline
\end{tabular}

of a systemic to pulmonary shunt that was considered a definitive surgery, due to the complexity of the heart defect. The mean time interval from the surgery to the interview was $9.83 \pm 3$ years. Eight patients had a palliative procedure before the corrective surgery (pulmonary artery banding in all of them) and two patients had a two-step corrective surgery. Patients were graded according to the severity of the procedure using the Risk Adjustment for Congenital Heart Surgery (RACHS) scale: Thirteen patients in category 1, 23 patients in category 2 , and 4 patients in category 3 . Seven patients needed a procedure after the corrective surgery, due to sequelae or complications (such as diaphragmatic paralysis, arrhythmia ablation, or subglottic stenosis). All patients were classified in category I according to the New York Heart Association functional class scale.

\section{Comparison of patients and controls}

Only one patient did not rank the school environment dimension because he did not attend school. Regardless of age and gender, patients scored higher than controls in all dimensions except for financial resources and social acceptance. The difference was largest in moods and emotions, autonomy, and parent relations (Fig. 1).

When comparing male patients with controls and female patients with controls, there was a tendency for a more positive rating in the male patient group in all dimensions. In contrast, female patients outranked female controls only in the dimensions of psychological well-being, moods and emotions, self-perception, autonomy, and parent relations.

Child (8-11 years) and adolescent (12-18 years) CHD patients scored higher in the moods and emotions, self-perception, autonomy, and parent relations, but scored lower in the social support and social acceptance dimensions. In the remaining dimensions, patients scored higher than controls when they were at the age of 12 years and older.

All comparisons were statistically significant $(p<0.0001)$.

\section{Comparison of subgroups of patients}

\section{COMORBIDITIES}

Nine patients had comorbidities: Four patients had a genetic syndrome (without associated cognitive impairment), two patients had hemifacial microsomia syndrome, one patient had Noonan syndrome, and one patient had 


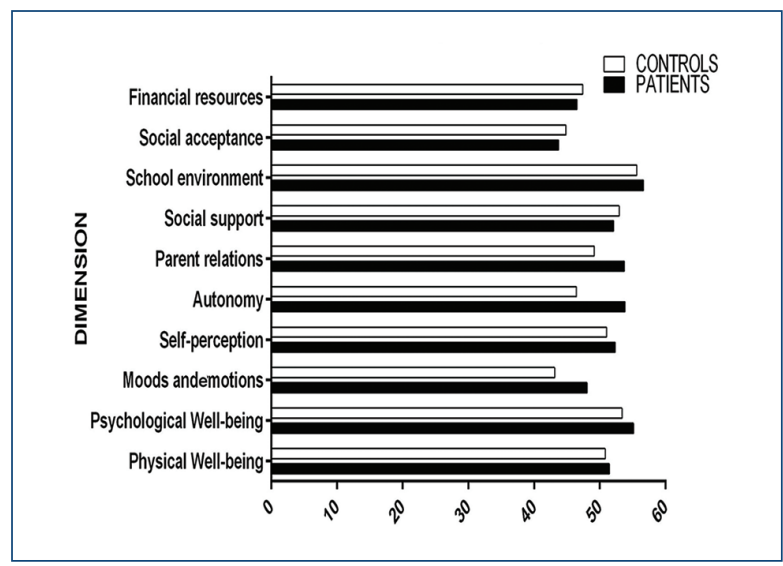

Figure 1. Congenital heart defect (CHD) group versus healthy control group. Comparison of means ranking quality of life in patients with CHD $(n=40)$ and in healthy controls $(n=80)$. All dimensions were statistically significant $(p<0.001)$.

an orofaciodigital syndrome. Two patients had asthma, one patient had congenital scoliosis, one patient had a post-intubation subglottic stenosis, and one patient had a speech sound disorder.

There were no significant differences between patients with and without comorbidities in any of the health-related QoL dimensions studied.

\section{Acyanotic Versus cyanotic HEART DEFECTS}

Patients with cyanotic defects reported higher QoL for the dimensions of physical well-being, mood and emotions, autonomy and financial resources; meanwhile, patients with acyanotic defects reported higher QoL for psychological well-being and school environment (mean 55.69 vs. 57.02 in cyanotic vs. acyanotic, respectively, $p=0.02$ ). In the other health-related QoL dimensions, scores were similar (Fig. 2).

\section{USE OF CARDIOPULMONARY BYPASS}

There were no significant differences in any health-related QoL dimension when comparing patients who underwent cardiopulmonary bypass with those who did not (Fig. 3).

\section{Procedures before and after the corrective SURGERY}

Patients without surgery before the corrective procedure reported higher QoL in the physical well-being

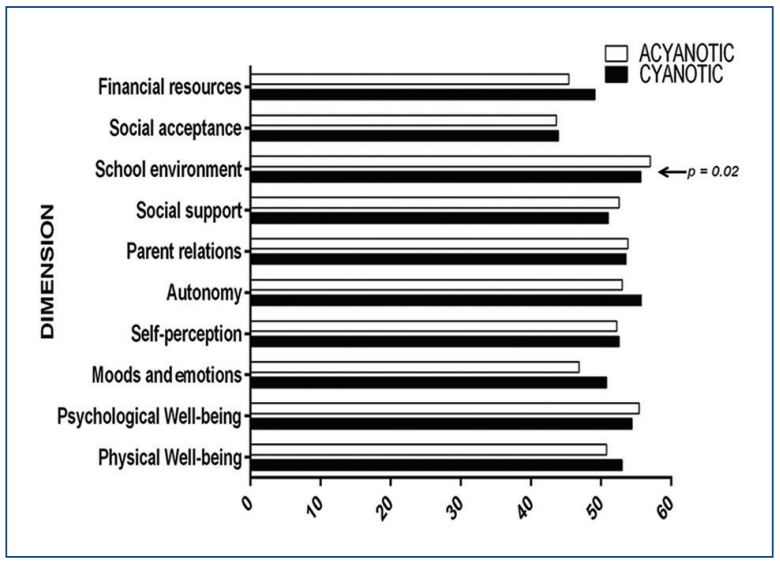

Figure 2. Cyanotic versus acyanotic. Comparison of means ranking quality of life between the patient group with cyanotic congenital heart defect (CHD) $(n=12)$ versus those with acyanotic CHD $(n=28)$. Statistical significance is given with $p$-values.

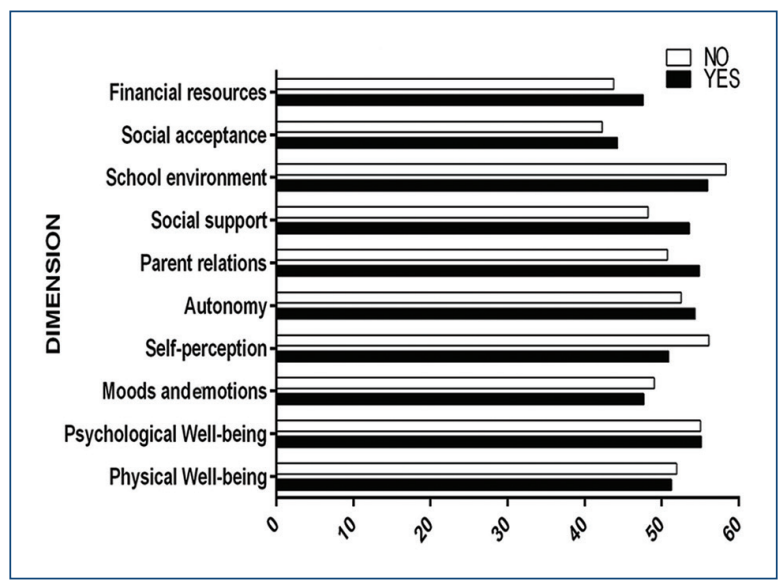

Figure 3. Cardiopulmonary bypass versus no cardiopulmonary bypass. Comparison of means ranking quality of life between the patient group who underwent correction using cardiopulmonary bypass $(n=29)$ versus those who did not $(n=11)$. There were no statistically significant values.

dimension and in the autonomy dimension. The difference in the autonomy dimension is statistically significant (mean 57.84 vs. $52.82, p=0.01$ ).

Patients who received CHD repair following a twostage surgery or having procedures and reinterventions after the corrective surgery rated higher in almost all dimensions, in particular, the dimensions of psychological well-being, self-perception, autonomy, parent relations, and school environment. They only rated lower for the dimensions of social support and social acceptance 


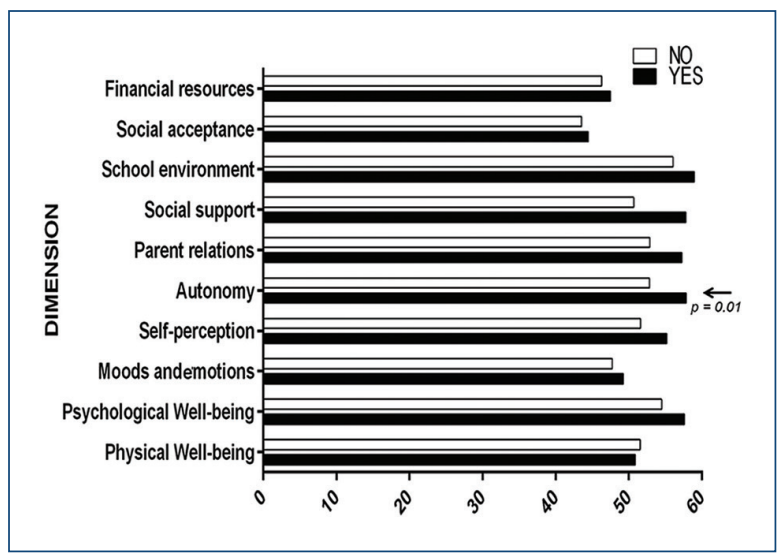

Figure 4. Previous procedures versus no previous procedures. Comparison of means ranking quality of life between the patient group with the previous procedures $(n=10)$ and those without previous procedures $(n=30)$. Statistical significance is given with p-values.

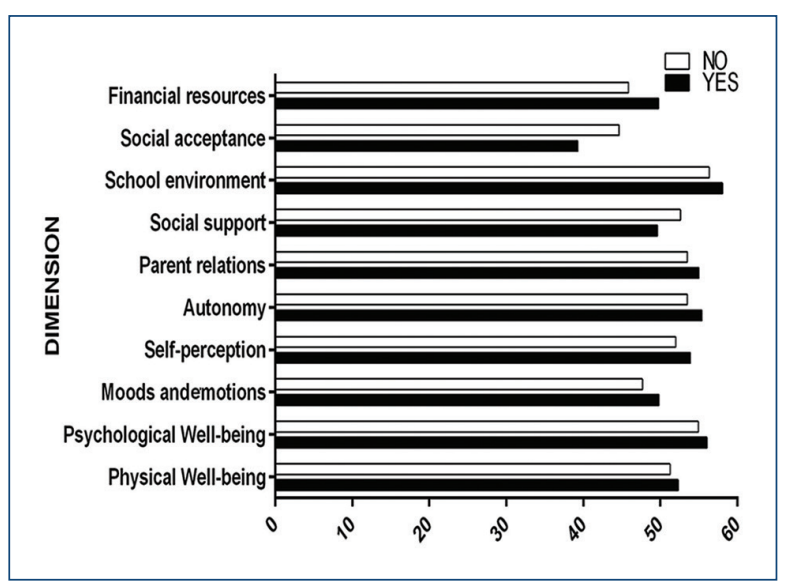

Figure 5. Reinterventions versus no reinterventions. Comparison of means ranking quality of life between the patient groups who required reinterventions $(n=7)$ against the group that did not require them $(n=33)$. There were no statistically significant values.

$(p=0.07)$ when compared to patients without reinterventions (Figs. 4 and 5).

\section{SEVERITY OF THE PROCEDURE}

When classifying patients according to the severity of the procedure and comparing each category with their paired control group, higher scores were obtained in the patient group in 8 out of 10 dimensions investigated. For the RACHS 1 and 2 categories, there were lower scores in the social acceptance dimension. For the RACHS 2, there was a lower score in the physical well-being dimension, and for the RACHS 3 category, a lower score was obtained in the moods and emotions and social support dimensions.

The only differences statistically significant were found in the category 2 in the dimensions of autonomy $(p=0.0002)$ and in parent relations $(p=0.0081)$, whereas in category 3 , it was found in the dimension of moods and emotions $(p=0.02)$.

\section{Discussion}

The results in the present study show that the self-reported QoL of children with CHD aged from 8 to 18 years was higher in almost all dimensions compared to their healthy controls. This finding is consistent with other studies, such as the one conducted by Reiner et al., who found that children and adolescents with CHD had a higher QoL compared to the healthy controls, without differences in the diagnostic subgroups and severity classes $^{16}$. Teixeira also found this in adolescents and young adults, with higher values of QoL in the environmental and social relationship scale ${ }^{17}$. In addition, a study by Bertoletti et al..$^{18}$ presents higher QoL in CHD when compared with the standard population.

The results obtained in our study could be influenced by the self-reported nature of the questionnaire and explained by the hypothesis of sense of coherence, which initially explained why some people undergoing a high level of stress become ill, and others remain healthy. Moons et al. used the term of sense of coherence to understand how patients with chronic diseases cope with their disease and are satisfied with their lives $^{19}$

A lower score in the financial resources dimension was found in the studied population, and it may reflect the low socioeconomic status of the sample population and their families since they are without a formal job and social security. It is a finding consistent in other studies, Amedro et al. found in his series that the parents tend to be unemployed and instead dedicate to the caretaking of their child ${ }^{20}$. Our patients, however, have developed coping strategies since very early stages of their life, which may explain the higher scores obtained in the dimensions of autonomy and parent relations, such coping strategies may be understood as resilience, a positive adaptive process from an individual in the context of extreme adversity, which is why patients with CHD have high levels of action in some dimensions of QoL despite facing adverse life conditions ${ }^{18}$. 
A Brazilian study conducted on 203 adolescents with CHD using the KIDSCREEN-27 questionnaire found no statistically significant difference between acyanotic and cyanotic groups, as well as for the different diagnostic subgroups. This is in accordance with our results, although one should note the small numbers and heterogeneity of our subgroups, and possible confounding factors should be considered ${ }^{16}$.

Related to the differences in age and sex, our study reported higher scores in all dimensions in patients older than 12 years, a finding contrary to the general population, where QoL declines with age, possibly due to the emotional and psychological adjustment. When $\mathrm{CHD}$ patients begin the adolescence, they may maintain a higher self-perception of QoL arising from the resilience concept explained before ${ }^{13,16,18}$.

A multilevel analysis in European children, conducted by Bisegger et al., showed that the decrease with aging in self-perception of QoL is more pronounced in females than males ${ }^{21}$. We reported in our patients higher scores in all dimensions in the male group when compared to their healthy control group.

A previous multicenter study in Europe evaluated QoL in patients with CHD and healthy controls, using the KIDSCREEN-52 questionnaire, revealing that physical well-being was lower for patients, influenced mainly by the severity of the disease adducing this to the stigma over CHD. Two other dimensions were lower in patients (financial resources and social support), a finding consistent with our own study. In a multivariate analysis, the dimension of autonomy was also lower than the control group, which could be explained because of overprotective parents.

When evaluating parents' reports on their perceived children's QoL, more dimensions were altered (school environment and psychological well-being) ${ }^{20}$.

When the RACHS scale was included in the analysis, higher scores in the three categories are consistent in the autonomy and moods and emotions dimensions, this emphasizes the idea that physical limitations are neither the only nor the most important factor for the health-related QoL, especially if coping styles, resilience and sense of coherence are well established. The impact of the type of heart defect and surgical procedure on the QoL has been evaluated, with variable results. Heush et al. found a trend toward lower scores in patients with univentricular physiology or after a Mustard procedure; however, they conclude that the surgical technique does not influence on the self-reported $\mathrm{QoL}^{22}$. On the other hand, Heye et al. compared QoL from patients with a single ventricle and those after a biventricular repair, finding a similar QoL in both groups ${ }^{23}$.

\section{Conclusions}

We conclude that the self-perception of QoL in post-operative patients for $\mathrm{CHD}$ is similar and in certain dimensions higher than the healthy population. Higher complexity studies that include psychosocial variables and parental perception are required. QoL is a subjective concept, and cultural differences from one region to another impact in the results obtained, research on this matter must be encouraged in every center that manages CHD. A better understanding of the QoL determinants will improve the attention provided to the patient and their families.

This is the first study of its kind in our country, and one of the few in developing countries addressing QoL after heart surgery. To the best of our knowledge, it is the third study that uses the KIDSCREEN questionnaire to evaluate QoL in CHD. No complete psychometric studies were performed. The small size of our sample is due to socioeconomic conditions of the patients attended in our hospital, making it hard to ensure a late follow-up. This also impacts on the small representativeness of the overall population in Mexico with CHD. Conducting studies in various centers of the country will allow for a better understanding of the QoL in general after heart surgery for CHDs in a developing country such as our own. Further studies with bigger samples, more variable heart diseases and a closer follow-up are required in our country. The type of survey-based research performed also implies a social desirability bias, which must be considered.

\section{Acknowledgments}

We wish to thank Rodolfo Delgadillo M.D. for the statistical support and Diana Reyes Ph.D. for the graphical technical support. We thank as well the following schools for their support with the control group: "Centro Pedagógico Latinoamericano," "Escuela Primaria Dr. Jesús Díaz de León," "Escuela Secundaria Jesús Reyes Heroles," and "Centro de Educación Media de la Universidad Autónoma de Aguascalientes."

\section{Funding}

This article was funded with personal funds. 


\section{Conflicts of interest}

The authors have no conflicts of interest to disclose. The design of the study, methods used, outcome parameters, analysis of data, and production of the written report were in their full control.

\section{Ethical disclosures}

Protection of human and animal subjects. The authors declare that the procedures followed were in accordance with the regulations of the relevant clinical research ethics committee and with those of the Code of Ethics of the World Medical Association (Declaration of Helsinki).

Confidentiality of data. The authors declare that they have followed the protocols of their work center on the publication of patient data.

Right to privacy and informed consent. The authors have obtained the written informed consent of the patients or subjects mentioned in the article. The corresponding author is in possession of this document.

\section{References}

1. van der Linde D, Konings EE, Slager MA, Witsenburg M, Helbing WA, Takkenberg JJ, et al. Birth prevalence of congenital heart disease worldwide: a systematic review and meta-analysis. J Am Coll Cardiol. 2011; 58:2241-7.

2. Mendieta-Alcántara GG, Santiago-Alcántara E, Mendieta-Zerón H, Dorantes-Piña R, Ortiz de Zárate-Alarcón G, Otero-Ojeda GA. Incidence of congenital heart disease and factors associated with mortality in children born in two hospitals in the state of Mexico. Gac Med Mex. 2013;149:617-23.

3. Venegas C, Peña-Alonso YR, Lozano R, Kofman-Alfaro S, Queipo G. Mortalidad por defectos al nacimiento. Bol Med Hosp Infant Mex. 2013;62:294-314.

4. Albert DC, Del Cerro MJ, Carrasco JL, Portela F. Actualización en cardiología pediátrica y cardiopatías congénitas, tratamiento quirúrgico. Rev Esp Cardiol. 2011;64:59-65.
5. García-Guereta L, Benito F, Portela F, Caffarena J. Novedades en cardiología pediátrica cardopatías congénitas del adulto y cirugía cardíaca de cardiopatías congénitas. Rev Esp Cardiol. 2010;63:29-39.

6. Varni JW, Seid M, Rode CA. The PedsQL: measurement model for the pediatric quality of life inventory. Med Care. 1999;37:126-39.

7. Uzark K, Jones K, Burwinke TM, Varni JW. The pediatric quality of life inventory in children with heart disease. Prog Pediatr Cardiol. 2003;18:141-8.

8. Moons P. Patient-reported outcomes in congenital cardiac disease: are they as good as you think they are? Cardiol Young. 2010;20 Suppl 3:143-8.

9. Marino BS, Cassedy A, Drotar D, Wray J. The impact of neurodevelopmental and psychosocial outcomes on health-related quality of life in survivors of congenital heart disease. J Pediatr. 2016;174:11-2200.

10. Velarde-Jurado E, Ávila-Figueroa C. Consideraciones metodológicas para evaluar la calidad de vida. Salud Publica Mex. 2002;44:448-63.

11. Carballés GF, Rodríguez OW, González GS, Aguilera SE, Consuegra CM. Calidad de vida en cardiopatías congénitos recontruidos quirúrgicamente incorporados a la rehabilitación cardíaca. Trece años de experiencia. Rev Cubana Cardio Cir Cardiovasc. 2014;20:85-90.

12. Castillo ME, Toro RL, Zelada PP, Herrera FL, Garay RV, Alcántara PA, et al. Calidad de vida en pacientes portadores de cardiopatías congénitas. Rev Chil Cardiol. 2010;29:57-67.

13. Bertoletti J, Marx GC, Hattge SP, Pellanda LC. Health-related quality of life in adolescents with congenital heart disease. Cardiol Young. 2015; 25:526-32.

14. Ravens-Sieberer U, Gosch A, Rajmil L, Erhart M, Bruil J, Duer W, et al. KIDSCREEN-52 quality-of-life measure for children and adolescents. Expert Rev Pharmacoecon Outcomes Res. 2005;5:353-64.

15. The KIDSCREEN Group Europe. The KIDSCREEN Questionnaires Quality of Life Questionnaires for Children and Adolescents. Lengerich, Germany: Pabst Science Publishers; 2006. p. 1-232.

16. Reiner B, Oberhoffer R, Ewert P, Müller J. Quality of life in young people with congenital heart disease is better than expected. Arch Dis Child. 2019;104:124-8.

17. Teixeira FM, Coelho RM, Proença C, Silva AM, Vieira D, Vaz C, et al. Quality of life experienced by adolescents and young adults with congenital heart disease. Pediatr Cardiol. 2011:32:1132-8.

18. Bertoletti J, Marx GC, Hattge Júnior SP, Pellanda LC. Quality of life and congenital heart disease in childhood and adolescence. Arq Bras Cardiol. 2014;102:192-8.

19. Moons $P$, Norekvål TM. Is sense of coherence a pathway for improving the quality of life of patients who grow up with chronic diseases? A hypothesis. Eur J Cardiovasc Nurs. 2006:5:16-20.

20. Amedro P, Dorka R, Moniotte S, Guillaumont S, Fraisse A, Kreitmann B, et al. Quality of life of children with congenital heart diseases: a multicenter controlled cross-sectional study. Pediatr Cardiol. 2015;36:1588-601.

21. Michel G, Bisegger C, Fuhr DC, Abel T, KIDSCREEN group. Age and gender differences in health-related quality of life of children and adolescents in Europe: a multilevel analysis. Qual Life Res. 2009;18:1147-57.

22. Heusch $A$, Kahl $H J$, Hensel $K O$, Calaminus $G$. Health-related quality of life in paediatric patients with congenital heart defects: association with the type of heart defect and the surgical technique. Qual Life Res. 2017;26:3111-7.

23. Heye KN, Knirsch W, Scheer I, Beck I, Wetterling K, Hahn A, et al. Health-related quality of life in pre-school age children with single-ventricle CHD. Cardiol Young. 2019;29:162-8. 